\title{
Is the IVS2+4T>C variant of the HFE gene a splicing mutation or a polymorphism? A study in the Spanish population
}

To the Editor:

Hereditary hemochromatosis $(\mathrm{HH})$ is one of the most common inherited metabolic abnormalities. It is inherited as an autosomal recessive trait, and the disease gene (HFE) has been mapped to the short arm of chromosome $6 .{ }^{1}$ There are three main mutations associated with HH: C282Y, H63D, and S65C. Other mutations described in different research projects have been reported. However, most of these mutations have been found in only one HH patient. One of them, IVS2 $+4 \mathrm{~T}>\mathrm{C}$, has been described as a likely splicing mutation. ${ }^{2}$ On the other hand, the proximity of the HFE gene to the major histocompatibility complex (MHC) has allowed different linkage disequilibria between MHC alleles (HLA) and HFE mutations to 
be identified: $\mathrm{C} 282 \mathrm{Y}$ and HLA-A3/B7 haplotype, H63D and HLA-A29/B44 haplotype, and S65C and HLA-A26 haplotype. ${ }^{3}$

The aims of this work are (1) to study whether the IVS2 $+4 \mathrm{~T}>\mathrm{C}$ variant may have a hemochromatosis phenotypic effect, and (2) to study whether this variant is in linkage disequilibrium with HLA alleles or haplotypes.

We studied 65 Spanish probands with a presumptive diagnosis of hemochromatosis that were heterozygous for $\mathrm{C} 282 \mathrm{Y}$ and negative for H63D and S65C. In addition, 86 unrelated, apparently healthy subjects were used as controls for the study. Finally, 23 individuals homozygous for the C282Y mutation and 31 for the H63D mutation were used in the study.

The HFE typing for the C282Y, H63D, and S65C mutations was performed as previously described. ${ }^{3}$ The HFE typing for the IVS2 + 4T $>$ C variant used the PCR-RFLP technique with the following primers: HFE2BF (CTTTGGGCTACGTGGATGACC) and HFE2BR (AAGCTCTGACAACCTCAGGAAGG). The IVS2 $+4 \mathrm{~T}>\mathrm{C}$ variant creates a $R$ saI site and the 239 base pairs (bp) PCR product digested with this enzyme was cut into two fragments of 197 and $42 \mathrm{bp}$. HLA-class I typing was performed by the standard complement-dependent microlymphocytotoxicity assay using commercially available alloantisera. Allele and haplotype frequencies were estimated using Arlequin V2.0 software. ${ }^{4}$

The allele frequency of the IVS2 $+4 \mathrm{~T}>\mathrm{C}$ variant was statistically different in the control group (34.8\%) from that in the heterozygous group for the C282Y mutation (16.2\%), $P=$ 0.009 . When we typed for IVS2 $+4 \mathrm{~T}>\mathrm{C}$ in 23 individuals homozygous for $\mathrm{C} 282 \mathrm{Y}$, none of them carried the intronic variant, indicating that the presence of the C282Y mutation excludes the presence of the IVS2 $+4 \mathrm{~T}>\mathrm{C}$ variant in the same chromosome. Thus, the real frequency of the intronic variant in the heterozygous group for the C282Y mutation is $32.4 \%$, which is not statistically different from the control group. If IVS2 $+4 \mathrm{~T}>\mathrm{C}$ were involved in generating a $\mathrm{HH}$ phenotype, we would expect to find an increased frequency of this variant in the heterozygous group for the $\mathrm{C} 282 \mathrm{Y}$ mutation. In addition, we have found $10(11.4 \%)$ individuals homozygous for the IVS2 $+4 \mathrm{~T}>\mathrm{C}$ variant in the apparently healthy group, leading us to think that this intronic variant is not a mutation that produces hemochromatosis.

The second aim of this work was to study the linkage disequilibrium of the IVS2 $+4 \mathrm{~T}>\mathrm{C}$ variant with HLA alleles and haplotypes. When we compared the HLA allelic and haplotypic frequencies of individuals homozygous for the IVS2 $+4 \mathrm{~T}>\mathrm{C}$ variant $(n=20)$ with individuals negative for this variant $(n=$ 70), we found an increased frequency of the HLA-A29/B44 haplotype in the group of individuals homozygous for the IVS2 $+4 \mathrm{~T}>\mathrm{C}$ variant ( $20 \%$ vs. $1.4 \%, P=0.008)$. It has been demonstrated that HLA-A29/B44 haplotype is in linkage disequilibrium with the H63D mutation. ${ }^{3,5}$ Next, we asked ourselves whether HLA-A29/B44_H63D_IVS2+4T $>$ C is an extended haplotype or if there are two different A29/B44 haplotypes: one carrying the IVS2 $+4 \mathrm{~T}>\mathrm{C}$ variant and the other carrying the H63D mutation. To answer this question, we studied the IVS2 $+4 \mathrm{~T}>\mathrm{C}$ variant in a group of 31 individuals homozygous for the H63D mutation. All of them turned out to be homozygous for the intronic variant while only $65 \%$ of chromosomes carrying the intronic variant were positive for the H63D mutation. This observation, together with the allele frequencies of H63D (20\%) and IVS2+4T $>$ C $(34.8 \%)$ in the normal population, allow us to think that IVS $2+4 \mathrm{~T}>\mathrm{C}$ is probably older than $\mathrm{H} 63 \mathrm{D}$.

In conclusion, our results suggest the IVS $2+4 \mathrm{~T}>\mathrm{C}$ variant is probably not a $\mathrm{HH}$ mutation. In addition, we have found the IVS2 $+4 \mathrm{~T}>\mathrm{C}$ variant is in linkage disequilibrium with the HLA-A29/B44 haplotype and is older than the H63D mutation.

\section{ACKNOWLEDGMENTS}

This work was supported in part by Fundación Lair.

$$
\begin{array}{r}
\text { Arantza Pacho de Lucas, BSc, } \\
\text { Maria Guzman Fulgencio, BSc, } \\
\text { Jorge Muñoz Robles, } M D, \\
\text { Esther Mancebo Sierra, BSc, } \\
\text { Manuel J. del Rey Cerros, BSc, } \\
\text { Pablo Morales Perez, PhD } \\
\text { Immunology } \\
\text { Hospital Universitario "12 de Octubre" } \\
\text { Madrid, Spain }
\end{array}
$$

\section{References}

1. Feder JN, Gnirke A, Thomas W, Tsuchihashi Z, Ruddy DA, Basava A et al. A novel MHC class I-like gene is mutated in patients with hereditary hemochromatosis. Nat Genet 1996;13:399-408.

2. de Villiers JNP, Hillermann R, Loubser L, Kotze MJ. Spectrum of mutations in the HFE gene implicated in haemochromatosis and porphyria. Hum Mol Genet 1999;8: $1517-1522$.

3. Pacho A, Mancebo E, del Rey MJ, Castro MJ, Oliver D, Berciano M et al. HLA haplotypes associated with hemochromatosis mutations in the Spanish population. BMC Med Genet 2004;5:25.

4. Schneider S, Roessli D, Excoffier L. Arlequin 2000: A software for population genetics data analysis. Geneva, Switzerland: Genetics and Biometry Laboratory, University of Geneva, 2000

5. Porto G, Alves H, Rodrigues P, Cabeda JM, Portal C, Ruivo A et al. Major histocompatibility complex class I associations in iron overload: evidence for a new link between the HFE H63D mutation, HLA-A29, and non-classical forms of hemochromatosis. Immunogenetics 1998;47:404-410. 